\title{
Adolescents' Conflict Resolution Styles Toward Mothers: The Role of Parenting and Personality
}

\author{
Lies Christine Missotten ${ }^{1}$ - Koen Luyckx ${ }^{1}$ Karla Van Leeuwen ${ }^{2}$ Theo Klimstra ${ }^{3}$. \\ Susan Branje ${ }^{4}$
}

Published online: 23 April 2016

(c) Springer Science+Business Media New York 2016

\begin{abstract}
In the present research, we examined associations between contextual and individual factors and adolescents' conflict resolution with mothers. In Study 1, we explored links between maternal responsiveness and psychological control and adolescent conflict resolution styles (positive problem solving, conflict engagement, withdrawal, and compliance) with two informants. In Study 2, we examined the unique contribution of adolescents' personality above and beyond perceived parenting in the prediction of conflict resolution styles. Results of both studies indicated that responsiveness was related positively to problem solving and negatively to withdrawal. Psychological control was positively associated with destructive resolution styles. Study 2 indicated that extraversion predicted more problem solving and conflict engagement, and less withdrawal. Agreeableness predicted more problem solving and less conflict engagement. Finally, certain personality traits moderated associations between parenting and conflict resolution, indicating that some adolescents are more sensitive to these parenting dimensions than others.
\end{abstract}

Lies Christine Missotten

Lies.Missotten@ppw.kuleuven.be

1 School Psychology and Child and Adolescent Development (SCAD), KU Leuven, Tiensestraat 102, Box 37, 3000 Leuven, Belgium

2 Parenting and Special Education, KU Leuven, Leopold Vanderkelenstraat 32, Box 3765, 3000 Leuven, Belgium

3 Department of Developmental Psychology, Tilburg University, Kamer P 2209, Box 90153, 5000 LE Tilburg, The Netherlands

4 Centre for Child and Adolescent Studies, Utrecht University, Heidelberglaan 1, 3584 CS Utrecht, The Netherlands
Keywords Adolescence - Conflict resolution · Parenting · Personality $\cdot$ Multi-informant

\section{Introduction}

Conflicts are an inevitable feature of human interactions. Especially in adolescence, conflicts with parents about everyday issues are common, mainly due to the realignment of the parent-adolescent relationship and adolescents' striving for autonomy (Collins and Laursen 2004). A metaanalysis by Laursen et al. (1998) revealed that conflicts with parents occur most frequently throughout early adolescence and decrease gradually thereafter. Such conflicts, however, are not necessarily detrimental for adolescent development. The way conflicts are managed is of crucial importance (Adams and Laursen 2007). A study by Branje et al. (2009) has indeed demonstrated that conflict resolution styles moderated the impact of conflicts on adolescents' adjustment.

Conflict resolution or management is defined as the behaviors people enact during a conflict. It is important to distinguish conflict management behaviors from conflict outcomes. Although both constructs are related, the former refers to behaviors that occur during conflicts whereas the latter refers to the effect or impact of the conflict (Laursen and Collins 1994). Inspired by Kurdek's (1994) work on conflict resolution in romantic couples and the literature on adolescent conflict (Laursen, 1993; Rubenstein and Feldman 1993; Van Doorn et al. 2008), we focused on four conflict resolution styles that adolescents use when they have disputes with their parents. Positive problem solving involves trying to understand the other's point of view and negotiating the conflict effectively to find a compromise. Conflict engagement involves destructive behaviors like 
attacking the other verbally, being defensive, or losing selfcontrol. Withdrawal involves avoiding the problem, avoiding talking, and becoming distant. Compliance involves giving into the other party without expressing one's point of view.

Conflict resolution styles have been associated with internalizing and externalizing problems, and social competence (Branje et al. 2009; Jaffee and D'Zurilla 2003). Further, adolescents' conflict resolution skills towards parents are expected to influence adolescent social functioning in various life domains as well (e.g., studies, peer, and romantic relationships). Recent work on adolescents' conflict behaviors has indeed demonstrated that both hostile and constructive conflict interactions with parents are transferred to peer relationships (Trifan and Stattin 2015; Van Doorn et al. 2011). Despite that these conflict resolution styles have been linked to a host of outcomes, research investigating antecedents that can explain individual differences in the use of these styles is scarce (Eisenberg et al. 2008).

In examining such potential antecedents, several developmental system theories stress the importance of integrating both individual and environmental factors in the study of adolescents' behavior (Kiff et al. 2011). The developmental-contextual model (Lerner et al. 2012), for instance, states that an individual's development is influenced by both dispositional factors and multiple nested contexts. The parenting context (microsystem) is especially relevant due to its proximal presence for adolescents' development. Hence, this model provides a conceptual framework for studying the unique contributions of parenting dimensions and personality characteristics, and their interaction on adolescent conflict styles. Objective 1 was to examine associations between the parenting dimensions of responsiveness and psychological control and the four conflict resolution styles in two studies, with Study 1 being multi-informant. Objective 2 was to examine associations between adolescents big five personality traits and conflict resolution above and beyond parenting (Study 2). Objective 3 was to investigate whether the associations between parenting and adolescents' conflict resolution styles differed depending on adolescents' personality (Study 2). Specific theorizing and hypotheses with respect to our study objectives can be found in the introductory sections of each study.

\section{Study 1}

Although peer interactions gain in importance during adolescence, the family remains an important context in which adolescents develop social skills (Sillars et al. 2004). Further, interacting with parents provides adolescents with a platform to learn how to deal with conflicts. Previous studies have demonstrated that conflicts occur more frequently in the family than in the peer context (Adams and Laursen 2001). In addition, the affective climate provided in the family has been recognized as a significant marker for the development of social competence (Laible and Carlo 2004). Because conflicts are emotional events (Jones 2001), we focus on two parenting dimensions that reflect the affective quality of parent-adolescent relationships (Duriez et al. 2007). The first dimension, responsiveness, is the parent's capacity to attune to children's needs and to react in a warm and involved manner in times of distress. The second dimension, psychological control, can be described as the use of manipulative techniques, such as guilt-induction, conditional loving, or shaming, that intrude in the child's psychological world (Barber 1996). These two affective parenting dimensions are especially relevant in the context of conflict management because unsupportive and controlling parenting has been related to higher levels of conflict frequency and intensity (Sturge-Apple et al. 2003; Yau and Smetana 1996). In addition, in the literature on romantic couples, responsiveness or support has been associated with more adequate problem solving, whereas the opposite was found for criticism and guilt induction (Sullivan et al. 2010).

To our knowledge, the associations between maternal responsiveness and psychological control and the four conflict resolution styles described above have not been examined thoroughly in the parent-adolescent literature. However, some studies have investigated associations between similar parent-child relationship variables and children's conflict-related behaviors. For instance, a hostile interaction style between parents and adolescents has been associated with adolescents' destructive problem solving skills (Capaldi et al. 1994; Rueter and Conger 1995). Psychological control is often accompanied by negative affect leading to a reduced sense of control (Barber, 1996), which, in turn, has been associated with greater display of both angry and withdrawn behavior (Havighurst et al. 2015; Manzeske and Stright 2009). Further, families with difficulties in dealing with autonomy processes (which are related to psychologically controlling parenting; Barber, 2002) appeared to have adolescents displaying more hostile conflict behaviors (Allen et al. 1996). Conversely, warm and consistent parenting (being strongly related to responsiveness) was associated with less attack and avoidance, and with more compromise and constructive problem solving (Rueter and Conger 1995; Tucker et al. 2003). Finally, Rubenstein and Feldman (1993) found that parental rejection was related to adolescents' reports of attack during conflicts, whereas family supportiveness was related to higher levels of adolescents' compromise and lower levels of avoidance. 
Several scholars have emphasized the importance of incorporating the perspective of the adolescent and the parent because these two interaction partners tend to have different views on parenting (Janssens et al. 2014; Spilt et al. 2015). Hence, this study adds to extant literature by using the perspectives of both adolescents and mothers, and by simultaneously examining the effects of two affectively different parenting dimensions on four conflict resolution styles. Based on our literature overview, we expected responsiveness to be associated with higher levels of positive problem solving and lower levels of conflict engagement and withdrawal. Psychological control is expected to be associated with higher levels of the more destructive resolution styles (i.e., conflict engagement and withdrawal). We also hypothesized a positive association between psychological control and compliance, because in a psychologically controlling climate adolescents might feel pressured to live up to their mothers' standards and this might result in a submissive attitude during conflicts (Assor et al. 2004, Mabbe et al. 2015). To rule out the possibility that the expected associations between parenting dimensions and conflict resolution styles might be driven by the possibly conflictual nature of the mother-adolescent relationship, we controlled for conflict frequency in all analyses.

\section{Method}

\section{Participants}

A total of 370 adolescents from grades $10-12$ of a secondary school in Flanders, the Flemish speaking part of Belgium, were invited to participate. The school mainly attracts middle-class Caucasian students. The final sample consisted of 274 adolescents (74\% response rate; $43.8 \%$ boys) and 194 mothers (52\% response rate). Adolescents' age ranged from 14 to 19 years $(M=16.53$ years, $S D=.96)$. Concerning family situation, $91.5 \%$ of the adolescents came from intact families. Mothers' age ranged from 39 to 57 years $(M=45.68$ years, $S D=3.04)$. With respect to maternal educational level, $9.4 \%$ had no degree, $24.6 \%$ finished secondary school, $55.5 \%$ had a bachelor degree, and $10.5 \%$ had a master degree.

\section{Procedure}

Prior to the study, all parents received an information letter, wherein they could refuse their child's participation. This resulted in exclusion of $<1 \%$ of the potential sample. On the day of data collection, all adolescents received an envelope with the questionnaire and an informed consent letter. About $7 \%$ of the adolescents did not give their assent to participate and were excluded. All participants were asked to fill out their questionnaires at home and give an envelope to their mother, including the questionnaire and an informed consent letter for the mothers. Enclosed envelopes with the completed questionnaires were returned to the school within 2 weeks. This procedure was approved by our university's Institutional Review Board.

\section{Measures}

All questionnaires detailed below were completed by adolescents and mothers.

\section{Conflict Resolution Styles}

Adolescents and mothers completed the Conflict Resolution Style Inventory (CRSI; Kurdek 1994). This questionnaire was originally designed to measure conflict resolution in couples, but was adapted for the parent-child context (Branje et al. 2009). The validity of this adapted measure has been demonstrated in various studies (Van Doorn et al. 2008). This questionnaire measures four conflict resolution styles (5 items each): positive problem solving, conflict engagement, withdrawal, and compliance. On a 5-point scale, ranging from 1 (never) to 5 (always), mothers and adolescents rated how often adolescents used particular conflict resolution strategies in relation to their mothers when they had a quarrel. Sample items included: "Trying to find solutions that are acceptable for both of us" (positive problem solving), "Letting myself go, and saying things I don't really mean" (conflict engagement), "Not listening to her anymore" (withdrawal), and "Not defending my opinion" (compliance). Cronbach's alphas for adolescent and mother reports were, respectively: Positive problem solving $(\alpha=.83$ and .81$)$, conflict engagement ( $\alpha=.75$ and .81$)$, withdrawal $(\alpha=.72$ and $.70)$, and compliance $(\alpha=.78$ and .81$)$.

\section{Conflict Frequency}

The frequency of conflicts between adolescents and mothers was measured with the Interpersonal Conflict Questionnaire (ICQ; Laursen 1993). This questionnaire consists of 35 items covering potential conflict topics that were rated on a 5-point scale ranging from 1 (never) to 5 (often). Adolescents and mothers rated for each item how often they had conflicts, disagreements, or quarrels with each other about a specific topic during the last week. All conflict topics refer to the adolescent's behavior and not the mother's behavior. Items included issues like: "behavior in class or school", "what time you have to be in or out of bed", and "cleaning, tidiness". Scores were averaged across the 35 items, providing average weekly conflict 
scores. Cronbach's alphas were .93 for the adolescent report and .94 for the mother report.

\section{Parenting Dimensions}

Responsiveness was assessed with a 7-item scale of the Child Report on Parent Behavior Inventory (CRPBI; Schaefer 1965; Schludermann and Schludermann 1988). A sample item reads "My mother often smiles to me". Psychological control was assessed with the 8-item Psychological Control Scale-Youth Self-Report (PCS-YSR; Barber 1996). A sample item reads "My mother is less friendly to me if I don't see thing as she does". All items were rated on 5-point Likert scale ranging from 1 (does not apply at all) to 5 (applies strongly). Adolescents reported on how they perceived their mothers' parenting behaviors and mothers reported on their own behaviors. The Dutch translations of these scales have been validated in several empirical studies (e.g., Soenens et al. 2006). Cronbach's alphas for adolescent and mother report, respectively, were: Responsiveness ( $\alpha=.90$ and .79 ), and psychological control $(\alpha=.78$ and .78$)$.

\section{Data Analyses}

To investigate the unique contribution of the parenting dimensions in predicting individual differences in conflict variables, we conducted hierarchical multiple regression analyses for the four dependent conflict styles separately (i.e., positive problem solving, conflict engagement, compliance, and withdrawal). First, we conducted regression analyses within informants, that is, we conducted all analyses for adolescent and mother reports separately. Second, we conducted regression analyses across informants, that is, we used adolescent-reported parenting variables as predictors of mother-reported conflict variables and vice versa. This latter set of analyses was conducted to remedy potential problems associated with single-informant bias. All regression analyses proceeded in two steps. In Step 1, adolescents' sex, age and conflict frequency were added as control variables. In Step 2, we added the two parenting dimensions.

\section{Results}

Means, standard deviations, and correlations are presented in Table 1. Standardized betas and $R^{2}$-values of the regression analyses are presented in Table 2. First, in the adolescent model, girls reported higher levels of withdrawal than boys, and according to mothers, younger adolescents displayed higher levels of compliance. In the across-informant models, younger adolescents displayed

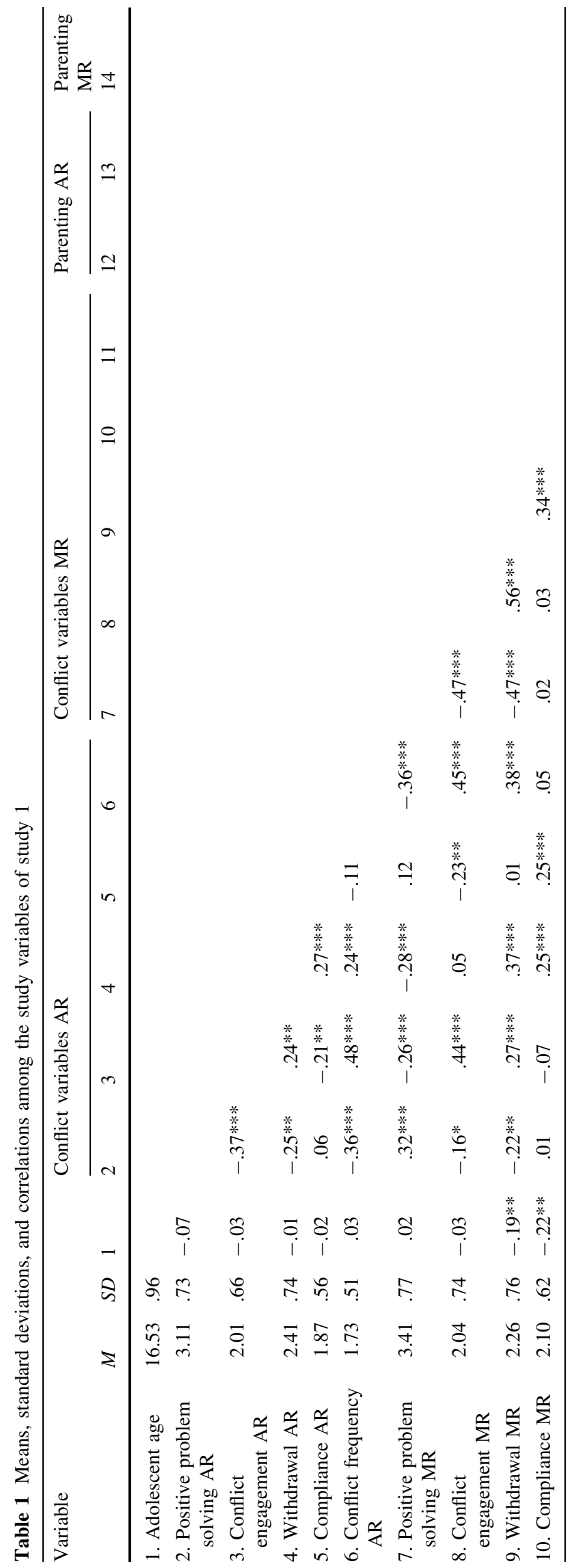




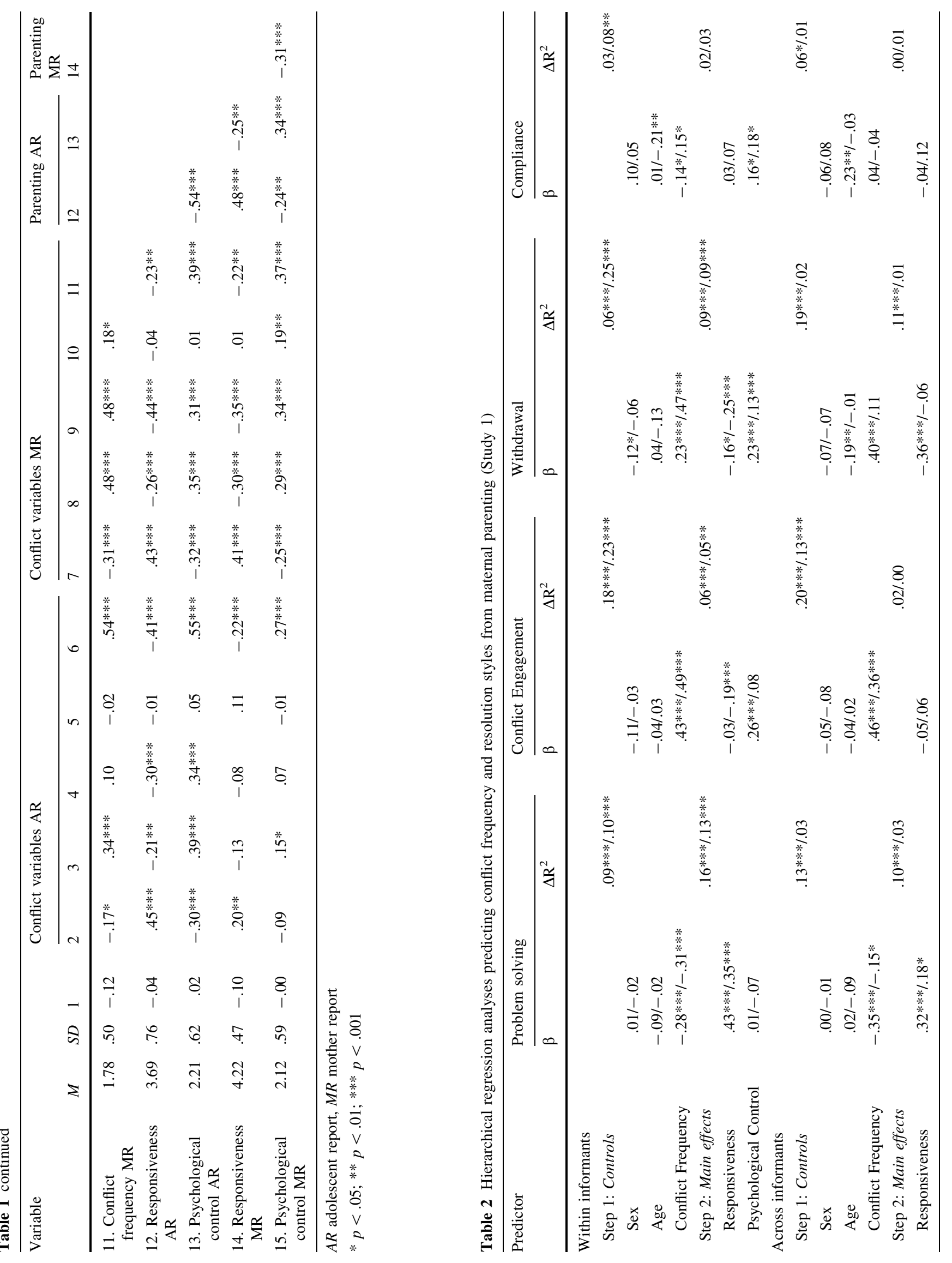




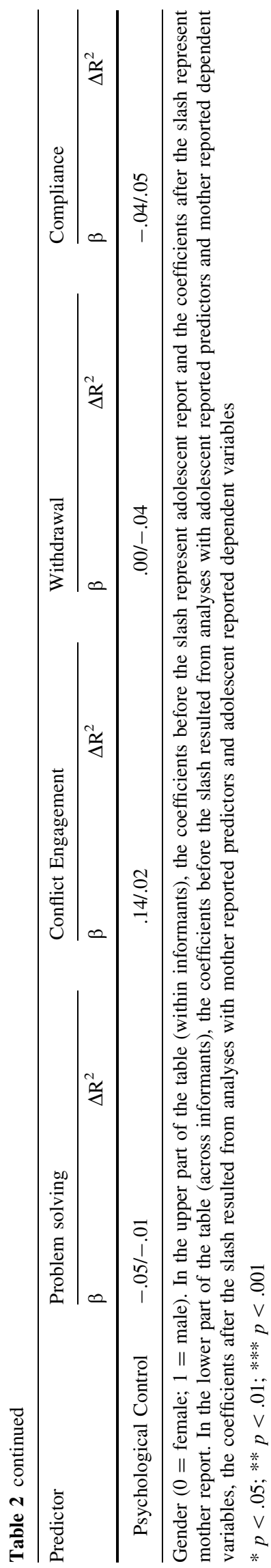

lower levels of withdrawal and compliance (only in the adolescent-reported-predictor model). Conflict frequency was a significant predictor for all conflict styles for both informants. For adolescents and mothers, conflict frequency was related positively to conflict engagement and withdrawal, and negatively to problem solving. In the across-informant analyses, conflict frequency was similarly related to problem solving and conflict engagement as in the within-informant analyses. Cross-informant, conflict frequency was also positively related to withdrawal but only in the adolescent-reported-predictor-mother-reportedoutcome model. The conflict style compliance was only related to conflict frequency in the within-informant models: for adolescents, more conflicts related to lower levels of compliance, whereas the opposite pattern appeared in the mother-reported model.

Second, concerning the main effects of parenting, responsiveness was associated positively with problem solving and negatively with withdrawal according to both adolescents and mothers. In the mother model only, a significant negative association between responsiveness and conflict engagement was found. These effects of responsiveness with the conflict styles were replicated in both across-informant models, with the exception of the association between responsiveness and withdrawal in the mother-reported-predictor-adolescent-reported outcome model. Psychological control was positively related to withdrawal and compliance according to adolescents and mothers. In the adolescent model only, psychological control was positively related to conflict engagement. These effects of psychological control with the conflict styles were not replicated in the across-informant models.

\section{Discussion}

In Study 1, responsiveness and psychological control seemed to predict conflict resolution largely in accordance with our expectations. Positive parenting seemed to predict more constructive conflict resolution, whereas negative parenting predicted more destructive styles. However, especially with respect to the resolution style of compliance, we did not find consistent meaningful associations with the parenting dimensions. This finding raises the question whether other factors, such as personality traits, might explain additional variance in the use of certain conflict resolution styles, or whether the prediction of certain conflict resolution styles by parenting might depend on adolescents' personality traits (being indicative of moderation). 


\section{Study 2}

The goal of Study 2 was twofold. First, we aimed to replicate the findings of Study 1 concerning the associations between parenting and conflict resolution and frequency (Objective 1). In doing so, adolescents reported about their conflict resolution styles with their mother and perceived maternal parenting. Second, as for Objective 2, we extended Study 1 by examining whether adolescents' personality traits uniquely predicted conflict behaviors above and beyond parenting dimensions. Third, as for Objective 3, we explored whether adolescents' susceptibility to parenting was dependent on their personality by examining the interaction effects of personality and parenting in the prediction of adolescent conflict resolution.

In line with person-environment interaction theories, a second potential determinant of adolescents' conflict resolution styles is their personality. Adolescents' personality traits can influence their conflict perceptions, affective responses during conflicts, and how much they value the relationship (Graziano et al. 1996; Park and Antonioni 2007). Most personality psychologists see dispositional traits, such as the widely used Big Five traits, as the basic layer of analysis when it comes to assessing personality (Caspi et al. 2005; McCrae and Costa 1987). Hence, we used these traits in Study 2: extraversion (energy, sociability, and experiencing frequent positive moods), agreeableness (kindness, empathy, and cooperativeness), conscientiousness (organizational and motivational aspects of behavior), emotional stability (the ability to deal with negative emotions), and openness to experience (the way an individual seeks and deals with new information).

Research on personality and conflict resolution has focused predominantly on two Big Five traits of crucial importance for interpersonal functioning: extraversion and agreeableness. Jensen-Campbell and Graziano (2001), Jensen Campbell et al. (2003) found that children's agreeableness was positively associated with constructive conflict management and negatively with destructive resolution tactics with peers. Other studies also have found positive associations of agreeableness and extraversion with collaboration (Antonioni 1998; Wood and Bell 2008). Extraversion was also related to higher levels of conflict engagement and lower levels of withdrawal (Park and Antonioni 2007).

Conscientiousness has also received some empirical attention in the context of interpersonal functioning (e.g., Jensen-Campbell et al. 2007; Jensen-Campbell and Malcolm 2007). Conscientiousness appears to be an important feature for maintaining satisfying interpersonal relationships because conscientious people are better able to inhibit aggressive responses when faced with interpersonal conflicts. Conscientious people score higher on affect regulation (Ahadi and Rothbart 1994), which might explain why they are less inclined to engage in destructive conflict behaviors. Next, emotional stability was positively related to problem solving and negatively to withdrawal and a focus on negative emotions (Connor-Smith and Flachsbart 2007). Finally, openness is the least understood big five dimension and associations between openness and conflict resolution have been somewhat contradictory. For instance, both positive and negative associations between openness and collaborative resolution have been found (Antonioni 1998; Park and Antonioni 2007).

Based on the abovementioned studies, we forwarded the following hypotheses concerning the associations between adolescents' personality traits and conflict resolution styles. Extraverted adolescents tend to experience positive emotions and high energy levels which might explain why they are less inclined to use passive strategies, such as withdrawal and compliance. We also expected extraversion to be positively associated with positive problem solving. However, due to their impulsiveness, they might also make use of conflict engagement (Caspi et al. 2005). Due to their motivation to sustain good relationships, agreeable people would engage more in problem solving and compliance and less in conflict engagement. We expected adolescents scoring low on emotional stability to engage less in positive resolution strategies and more in attacking or avoidant strategies, due to their heightened sensitivity for negative affect and lower impulse control (McCrae and Costa 1987). The organized and disciplined nature of conscientious adolescents would facilitate problem solving and reduce the use of conflict engagement (McCrae and John 1992). Finally, we tentatively expected openness to be positively related to positive problem solving and negatively to withdrawal, because open-minded people have the cognitive capacity to take on different perspectives when having a conflict (McCrae and Costa 1997).

Personality traits may not only function as an important predictor of conflict resolution, but could also make adolescents more (or less) sensitive to the effects of both positive and negative parenting on their conflict resolution behaviors. The goodness-of-fit model (Thomas and Chess 1977) has inspired the development of more specific person-environment frameworks, such as the diathesis-stress (or dual-risk) model (Monroe and Simons 1991) and the model of differential susceptibility (Pluess and Belsky 2013). Studies investigating these interactions from a diathesis-stress perspective have focused on the combined impact of adverse parenting and certain personality traits on negative child outcomes (e.g., Prinzie et al. 2003). Such studies have found, for instance, that when children with a less adaptive personality profile are confronted with 
adverse parenting, they score higher on behavior problems. This model stresses the dark side of susceptibility by focusing on deleterious risk factors and environments. Conversely, the vantage-sensitivity perspective posits that children scoring high on adaptive personality traits benefit more from a supportive environment (Pluess and Belsky 2013). Finally, the differential-susceptibility hypothesis integrates both models into a single model by stating that certain personality factors are plasticity factors that make individuals more sensitive to their environment for better and for worse.

In line with theorizing on person-environment interactions and primarily in line with the diathesis-stress perspective, previous research has already found that children's personality traits moderated the relationship between parenting and children's externalizing behaviors. For instance, unsupportive and overreactive parenting was not related to behavioral problems for children scoring high on agreeableness, conscientiousness, and extraversion as opposed to children scoring low on these same personality characteristics (Prinzie et al. 2003; Van Leeuwen et al. 2004). With regard to openness, De Haan et al. (2010) found that overcontrolling parenting was associated with more aggressive behaviors for more imaginative (open) children. These findings suggest that less open, and more agreeable, extraverted, conscientious children are less vulnerable to the effects of unsupportive parenting or, vice versa, that children scoring with the opposite personality profile are more vulnerable to adverse parenting. A recent study by Mabbe et al. (2015) investigated the moderating role of adolescents' personality traits in the association between maternal psychological control and externalizing behaviors. Adolescent scoring low on agreeableness appeared to be more sensitive for the adverse effects of psychological control, whereas highly agreeable adolescents were not affected by psychological control.

In line with the vantage-sensitivity perspective, Meunier et al. (2011) found that having a supportive mother was a protective factor against externalizing behaviors, especially for more introverted and agreeable children. These children seemed to benefit from their mothers' support as opposed to their more extraverted and less agreeable peers. In line with the differential-susceptibility model, Lengua (2008) demonstrated that more neurotic children displayed higher levels of externalizing problems when mothers were rejecting but lower levels of externalizing problems when mothers manifested little rejection.

In the present study, we investigated similar moderation effects of adolescents' personality on the associations between parenting and adolescent conflict resolution styles. However, with respect to conflict resolution, it is difficult to forward concrete hypotheses due to a lack of previous research, but we expect that similar mechanisms could occur. Based on the aforementioned studies on externalizing behavior and in line with the diathesis-stress perspective, we tentatively expected that the link between high levels of psychological control and more destructive conflict strategies might be more pronounced for adolescents with a more vulnerable or less mature personality profile (i.e., low scores on agreeableness, conscientiousness, and/ or extraversion). In other words, psychological control might be more strongly related to the use of withdrawal and conflict engagement for less agreeable, conscientious, and extraverted adolescents. Highly agreeable, extraverted, or conscientiousness adolescents might be less affected by such adverse parenting dimensions. Finally, based on the findings of Meunier et al. (2011) and in line with the vantage-sensitivity perspective, we expected that more introverted and agreeable adolescents would benefit most from mothers' responsive parenting by using lower levels of aggressive resolution styles or higher levels of problem solving. The positive effects of responsive parenting might be stronger for these adolescents because they experience a good fit between their personality and their home environment (Belsky 2005).

It should be noted, however, that externalizing behaviors and conflict resolution styles are different constructs and therefore our interaction hypotheses remained tentative. Nonetheless, both sets of constructs do share some characteristics. Externalizing and internalizing behaviors are often operationalized with the Youth Self Report (YSR, Achenbach 1991) and some of the subscales are withdrawal, social problems, and aggressive behavior (i.e., all indicators of adolescents' behaviors in social situations). In addition, conflict resolution styles have been related to externalizing and internalizing problems (Branje et al. 2009).

\section{Method}

\section{Participants}

A total of 407 adolescents were recruited from grades 9-12 of two secondary schools in Flanders, Belgium. They attended schools which mainly attract middle-class Caucasian students. The final sample consisted of 377 adolescents (92.6\% response rate). Adolescents' age ranged from 13 to 19 years $(M=16.01$ years, $S D=1.23,74.3 \%$ boys). Concerning family situation, $80.6 \%$ of the adolescents came from intact families.

\section{Procedure}

The procedure adopted in Study 2 was similar to that of Study 1 . Less than $1 \%$ of the potential sample did not get parental permission to participate. On the day of the data 
collection, about $5 \%$ of the adolescents did not give their assent to participate in our study and were excluded. All participants were asked to fill out the questionnaires in the classroom.

\section{Measures}

Instruments were virtually identical to Study 1, with some differences as described below. Adolescents answered all questionnaires concerning conflict behaviors and parenting with respect to their mother.

\section{Conflict Resolution Styles}

As in Study 1, adolescents completed the CRSI (Kurdek 1994). Cronbach's alphas for adolescents' resolution styles towards mother were: Positive problem solving $(\alpha=.78)$, conflict engagement ( $\alpha=.78)$, withdrawal ( $\alpha=.73$ ), and compliance $(\alpha=.69)$.

\section{Conflict Frequency}

The frequency of conflicts between adolescents and mothers was measured with the shortened 11-item version (Branje et al. 2009) of the ICQ (Laursen 1993). Cronbach's alpha was .82.

\section{Parenting Dimensions}

Psychological control and responsiveness were assessed with the same instruments as described in Study 1. Adolescents reported about how they perceived their mothers' parenting behaviors. Cronbach's alphas were .89 for responsiveness and .81 for psychological control.

\section{Adolescents' Personality Traits}

Adolescents completed the Quick Big Five, a shortened Dutch version of Goldberg's Big Five measure (Goldberg 1992; Vermulst and Gerris 2005). This questionnaire consists of 30 unipolar markers, which have to be rated on a 7 -point scale $(1=$ completely untrue, $7=$ completely true). Sample items are: talkative (Extraversion), sympathetic (Agreeableness), systematic (Conscientiousness), nervous (Emotional Stability), and creative (Openness). Cronbach's alphas were $.80, .83, .76, .71$, and .72, respectively.

\section{Data Analyses}

We performed multiple regression analyses for the four dependent conflict resolution styles separately. In Step 1, we entered age, sex, and conflict frequency as control variables. In Step 2, we added perceived maternal parenting. Personality traits were added in Step 3. In Step 4, we added the interaction terms of each parenting dimension with each Big Five personality trait. We first standardized all independent terms before calculating interaction terms (Cohen et al. 2003). We only interpreted individual significant interaction terms if the chunk test indicated a significant increase in $R^{2}$ (Jaccard and Turrisi 2003). To evaluate whether the statistical significant interaction effects supported the diathesis-stress, vantage sensitivity or differential susceptibility hypothesis, we calculated the following indices with a web application (Fraley 2012) as recommended by Roisman et al. (2012). Regions of Significance $(\mathrm{RoS})$ indicate the range of the parenting variable for which the association between the personality trait and the conflict style is statistically significant. When RoS are only found on the negative end of the parenting variable, diathesis stress is supported. Vantage sensitivity is supported when the interaction RoS are only found on the positive end of the parenting variable, whereas differential susceptibility is supported when RoS is significant on both ends of the parenting variable. The crossover point (C) indicates the point in the $\mathrm{x}$-axis where the regression lines intersect. The Proportion of Interest (PoI) represents the proportion of the interaction presented on the left versus the right side of $\mathrm{C}$, and the Proportion of Affected (PA) represents the proportion of cases on the parenting variable that are situated on the left versus the right side of $\mathrm{C}$. The results are in favor of diathesis stress when $\mathrm{C}$ is situated at the positive side of the parenting variable and PoI/PA values on the positive side are closer to $0 \%$. The opposite is in favor of vantage sensitivity. Differential susceptibility can be forwarded when $\mathrm{C}$ is situated within the range of the parenting variable and PoI/PA values are closer to $50 \%$ on both sides of $\mathrm{C}$.

\section{Results}

Descriptive statistics and correlations are presented in Table 3. Table 4 presents the standardized betas and $R^{2}$ values of the regression analyses. In Step 1, sex added significantly to the prediction of positive problem solving and conflict engagement, indicating that girls used both conflict styles more than boys. Age was positively related to conflict engagement and withdrawal, indicating that older adolescents tend to rely more on these two styles. Conflict frequency was related negatively to problem solving and positively to the other three styles. Parenting (Step 2) added significantly to the prediction of all outcomes. The findings of Study 2 replicated those of Study 1 adequately. Responsiveness was associated with more positive problem solving and less withdrawal. 


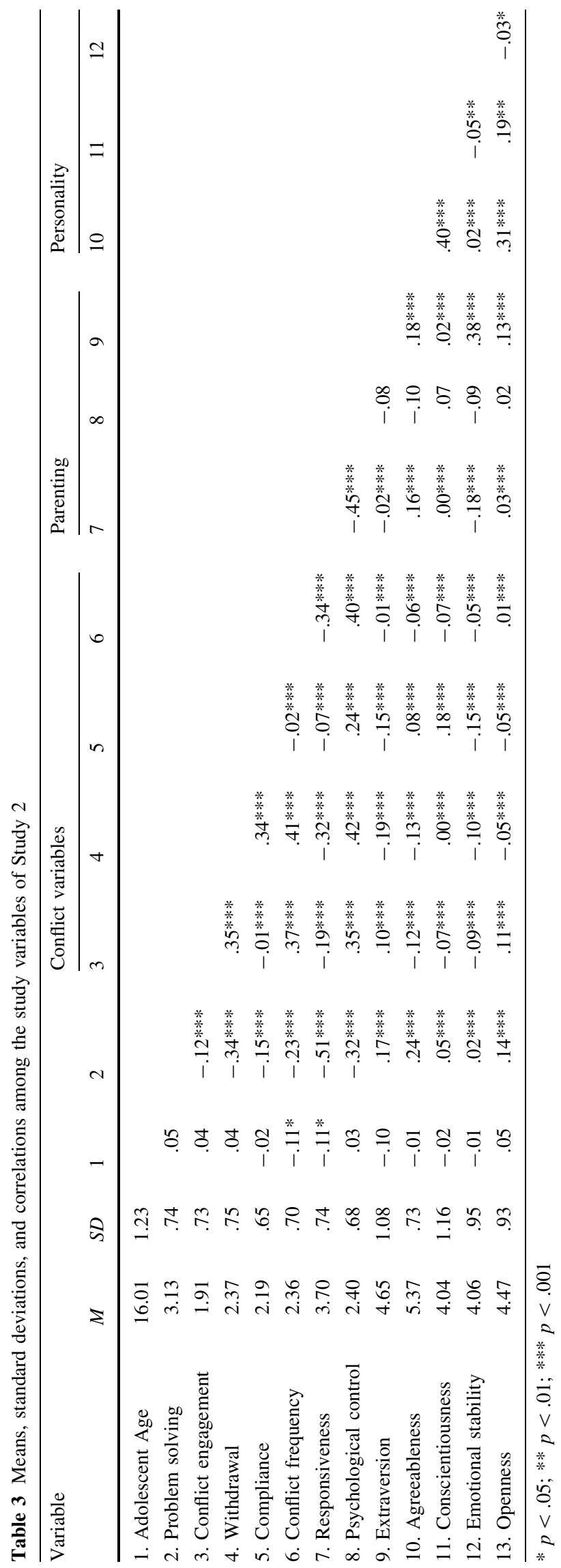

Psychological control predicted higher levels of conflict engagement, withdrawal, and compliance.

Big Five personality traits (Step 3) explained a significant additional proportion of variance in all four conflict styles. However, the amount of explained variance by personality traits was lower than that of parenting, except for compliance. As expected, extraversion predicted higher levels of positive problem solving and conflict engagement, and lower levels of withdrawal. In line with our expectations, agreeableness was associated positively with positive problem solving and negatively with conflict engagement. Conscientiousness predicted more compliance. Emotional stability was not related to any of the outcome variables. Finally, contrary to our expectations, openness was positively associated with conflict engagement. Hence, although we found positive bivariate correlations between openness and both positive problem solving and conflict engagement, openness uniquely predicted more conflict engagement (but not more problem solving) when controlling for the other traits.

Finally, 9 out of 40 possible interaction effects reached significance. Before discussing each of these significant interactions, readers should note that only 2 interactions (i.e., responsiveness $\times$ extraversion in the prediction of problem solving, and responsiveness $\times$ openness in the prediction of withdrawal) survived the conservative adjusted Bonferroni alpha value of $.005(\alpha / \mathrm{n}=.05 / 10)$. This is a technique to adjust the $p$ value to control for multiple testing. Nonetheless, we chose to report and interpret all significant interaction effects (given a significant chunk-test) because Bonferroni correction comes with several problems as well, such as loss of statistical power and increased Type II error (Nakagawa 2004).

The interaction effects of responsiveness with the Big Five traits added significantly to the prediction of problem solving, withdrawal, and compliance. With respect to problem solving, the interaction between responsiveness and extraversion was significant. The interaction was only significant at the left side of $\mathrm{C}$ (for low levels of responsiveness), and PoI/PA indices were closer to zero, supporting the diathesis-stress hypothesis (see Fig. 1 for details). Hence, lower scores on responsiveness were related to relatively lower problem solving, especially for introverted adolescents.

With respect to withdrawal, the interactions (a) between responsiveness and agreeableness, and (b) between responsiveness and openness were significant. (a) For agreeableness, the interaction was only significant at the right side of $\mathrm{C}$ (for high levels of responsiveness), and $\mathrm{PoI} /$ PA indices were close to $100 \%$, supporting the vantagesensitivity hypothesis. Hence, higher levels of responsiveness were associated with less withdrawal, especially for highly agreeable adolescents. (b) For openness, we 
Table 4 Hierarchical regression analyses predicting conflict resolution styles from maternal parenting and Big Five personality traits (Study 2)

\begin{tabular}{|c|c|c|c|c|c|c|c|c|}
\hline \multirow[t]{2}{*}{ Predictor } & \multicolumn{2}{|c|}{ Problem solving } & \multicolumn{2}{|c|}{ Conflict engagement } & \multicolumn{2}{|c|}{ Withdrawal } & \multicolumn{2}{|c|}{ Compliance } \\
\hline & $\beta$ & $\Delta \mathrm{R}^{2}$ & $\beta$ & $\Delta \mathrm{R}^{2}$ & $\beta$ & $\Delta \mathrm{R}^{2}$ & $\beta$ & $\Delta \mathrm{R}^{2}$ \\
\hline Step 1: Controls & & $.07 *$ & & $.16^{* * *}$ & & $.18 * * *$ & & $.03 *$ \\
\hline Sex & $-.12^{*}$ & & $-.15^{* *}$ & & -.09 & & .02 & \\
\hline Age & .05 & & $.11 *$ & & $.10^{*}$ & & -.01 & \\
\hline Conflict frequency & $-.22 * * *$ & & $.39 * * *$ & & $.43 * * *$ & & $.16^{* *}$ & \\
\hline Step 2: Main effects & & $.21 * * *$ & & $.06 * * *$ & & $.10 * * *$ & & $.04 * * *$ \\
\hline Responsiveness & $.47 * * *$ & & -.02 & & $-.15^{* *}$ & & .06 & \\
\hline Psychological control & -.10 & & $.26 * * *$ & & $.27 * * *$ & & $.23 * * *$ & \\
\hline Step 3: Main effects & & $.05 * * *$ & & $.05 * * *$ & & $.03 * *$ & & $.07 * * *$ \\
\hline Extraversion & $.14^{* *}$ & & $.16^{* *}$ & & $-.16^{* * *}$ & & -.11 & \\
\hline Agreeableness & $.11^{*}$ & & $-.13 *$ & & -.06 & & .09 & \\
\hline Conscientiousness & .00 & & -.05 & & -.03 & & $.16^{* *}$ & \\
\hline Emotional stability & .04 & & -.07 & & .01 & & -.08 & \\
\hline Openness & .07 & & $.12 *$ & & -.02 & & -.10 & \\
\hline \multicolumn{9}{|l|}{ Step 4: Interaction effects } \\
\hline & & $.03 * *$ & & .01 & & $.03 *$ & & $.04 *$ \\
\hline Resp $\times$ extr & $-.19 * * *$ & & -.05 & & .04 & & .01 & \\
\hline Resp $\times$ agre & .01 & & .06 & & $-.16^{* *}$ & & $-.14^{*}$ & \\
\hline Resp $\times$ consc & .01 & & .05 & & .00 & & $.13^{*}$ & \\
\hline Resp $\times$ emo & .04 & & .01 & & .02 & & $.13^{*}$ & \\
\hline \multirow[t]{2}{*}{ Resp $\times$ open } & .04 & & -.03 & & $.14 * *$ & & .09 & \\
\hline & & .01 & & .01 & & .01 & & $.04 *$ \\
\hline Psyc $\times$ extr & .04 & & .04 & & -.04 & & $-.11 *$ & \\
\hline Psyc $\times$ agre & $-.13^{*}$ & & -.07 & & .07 & & $.12^{*}$ & \\
\hline Psyc $\times$ consc & .01 & & -.03 & & -.02 & & -.03 & \\
\hline Psyc $\times$ emo & .01 & & -.04 & & -.01 & & -.02 & \\
\hline Psyc $\times$ open & .03 & & .01 & & -.03 & & $-.15^{* *}$ & \\
\hline
\end{tabular}

Gender $(0=$ female; $1=$ male $)$

$* p<.05 ; * * p<.01 ; * * * p<.001$

found evidence for differential susceptibility, because the interaction was significant at both ends of $\mathrm{C}$, and the PoI/ PA indices were close to $50 \%$. Hence, adolescents scoring low on openness exhibit more withdrawal in a low responsive climate and less withdrawal in a highly responsive climate than their more open peers. The latter seem unaffected by responsiveness. Both interactions are presented in Fig. 2.

With respect to compliance, responsiveness interacted significantly with (a) agreeableness, (b) emotional stability, and (c) conscientiousness. (a and b) For agreeableness and emotional stability, the interaction was only significant at the left side of $\mathrm{C}$ (for low levels of responsiveness), and PoI/PA indices were closer to zero, supporting the diathesis stress hypothesis. Hence, lower scores on responsiveness were related to relatively higher scores on compliance for more agreeable and less emotionally stable adolescents. Given the similarity of both interactions, only the interaction with agreeableness is presented in Fig. 3a. (c) For conscientiousness, we found evidence for the vantage- sensitivity hypothesis because the interaction was only significant at the right side of $\mathrm{C}$ (for high levels of responsiveness), and $\mathrm{PoI} /$ PA indices were closer to $100 \%$. For less conscientious adolescents, higher scores on responsiveness were related to less compliance (see Fig. 3b).

Further, psychological control interacted significantly with extraversion, agreeableness, and openness in the prediction of compliance. All three interaction effects were significant at the right side of $\mathrm{C}$ (for high levels of psychological control) scores, and PoI/PA indices were closer to zero on the positive side of $\mathrm{C}$, supporting diatheses stress. Hence, higher scores on psychological control were associated with higher levels of compliance, especially for less extraverted, more agreeable, and less open adolescents. Given the similarity in these three interactions, only the interaction with openness is displayed in Fig. 4. 


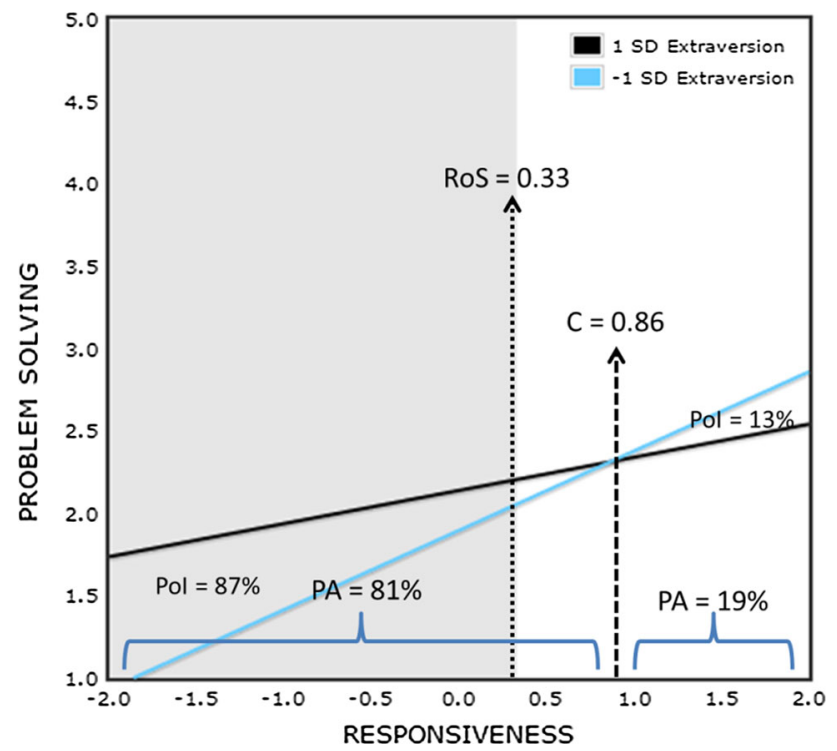

Fig. 1 Simple slopes of responsiveness predicting positive problem solving at varying levels of extraversion. High levels are $1 S D$ above the mean; low levels are $1 S D$ below the mean. The grey area represents the region of significance (RoS). The dotted line respresents the endpoint of the RoS on the $\mathrm{X}$-axis. The dashed line indicates the cross-over point $(\mathrm{C})$ of the regression lines on the $\mathrm{X}$-axis. The proportion of Interest (PoI) is the triangular area formed by the regression lines and this is the proportion of the interaction represented on the left versus right side of $\mathrm{C}$. The proportion of Affected (PA) is calculated on the sample frequency of responsiveness and shows the proportion of reported levels of responsiveness higher than $\mathrm{C}$

\section{Discussion}

The effects of parenting on adolescents' conflict resolutions obtained in Study 2 replicated the findings obtained in Study 1. In addition, several personality traits predicted adolescents' conflict styles. Positive problem solving was positively predicted by extraversion and agreeableness. Conflict engagement was negatively predicted by extraversion and agreeableness and positively by openness. Withdrawal was negatively predicted by extraversion, and compliance was positively predicted by conscientiousness. Several parenting by personality interactions were significant, showing that associations between parenting and adolescents' conflict resolution styles differed depending on adolescents' personality. In the next section, we provide an integrative discussion of the findings of both studies.

\section{General Discussion}

The present study sheds light on the associations between the two parenting dimensions of responsiveness and psychological control and adolescents' conflict resolution styles with mothers. In Study 2, adolescents' personality

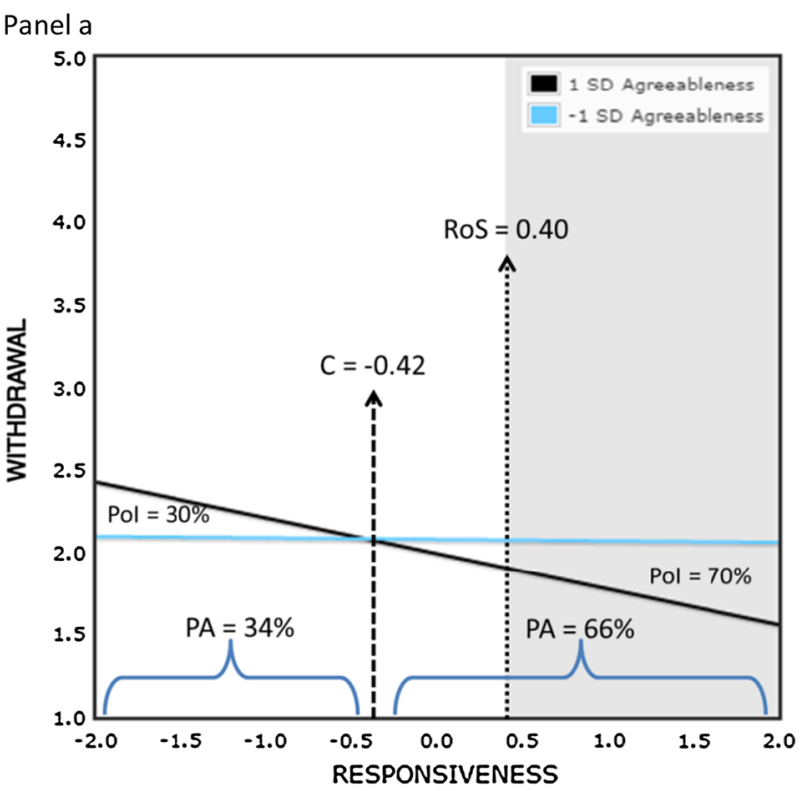

Panel b

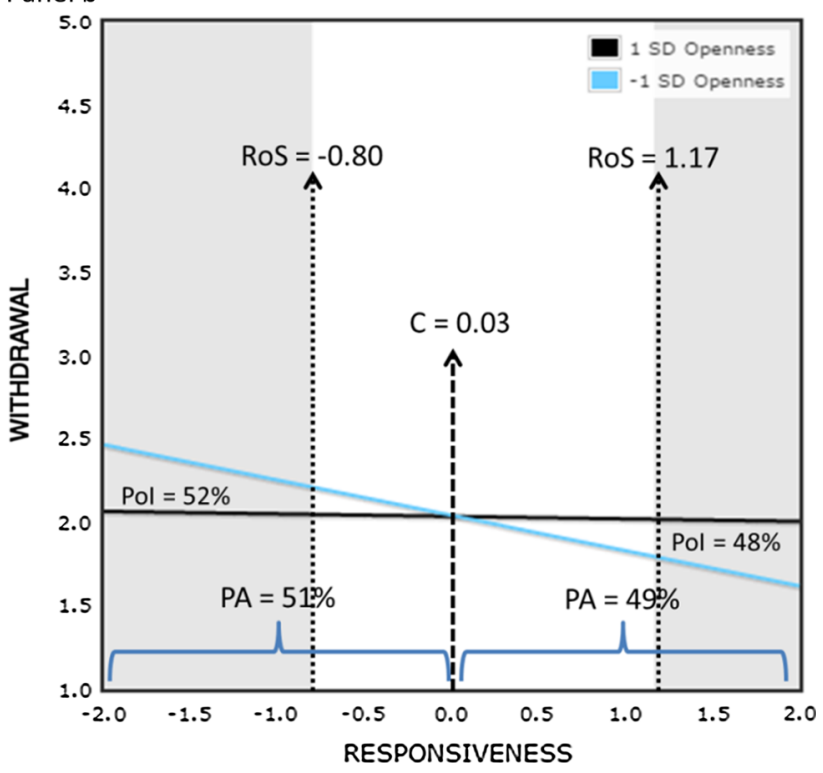

Fig. 2 Simple slopes of responsiveness predicting withdrawal at varying levels of agreeableness (panel a), and openness (panel b). High levels are $1 S D$ above the mean; low levels are $1 S D$ below the mean. The grey areas represent the regions of significance (RoS). The dotted lines represent the endpoints of the RoS on the X-axis. The dashed line indicates the cross-over point $(\mathrm{C})$ of the regression lines on the $\mathrm{X}$-axis. The proportion of Interest (PoI) is the triangular area formed by the regression lines and this is the proportion of the interaction represented on the left versus right side of $\mathrm{C}$. The proportion of Affected (PA) is calculated on the sample frequency of responsiveness and shows the proportion of reported levels of responsiveness higher than $\mathrm{C}$

traits were also included as individual determinants to examine their unique value in the prediction of conflict behaviors above and beyond parenting. Both parenting and personality were uniquely and significantly associated with 

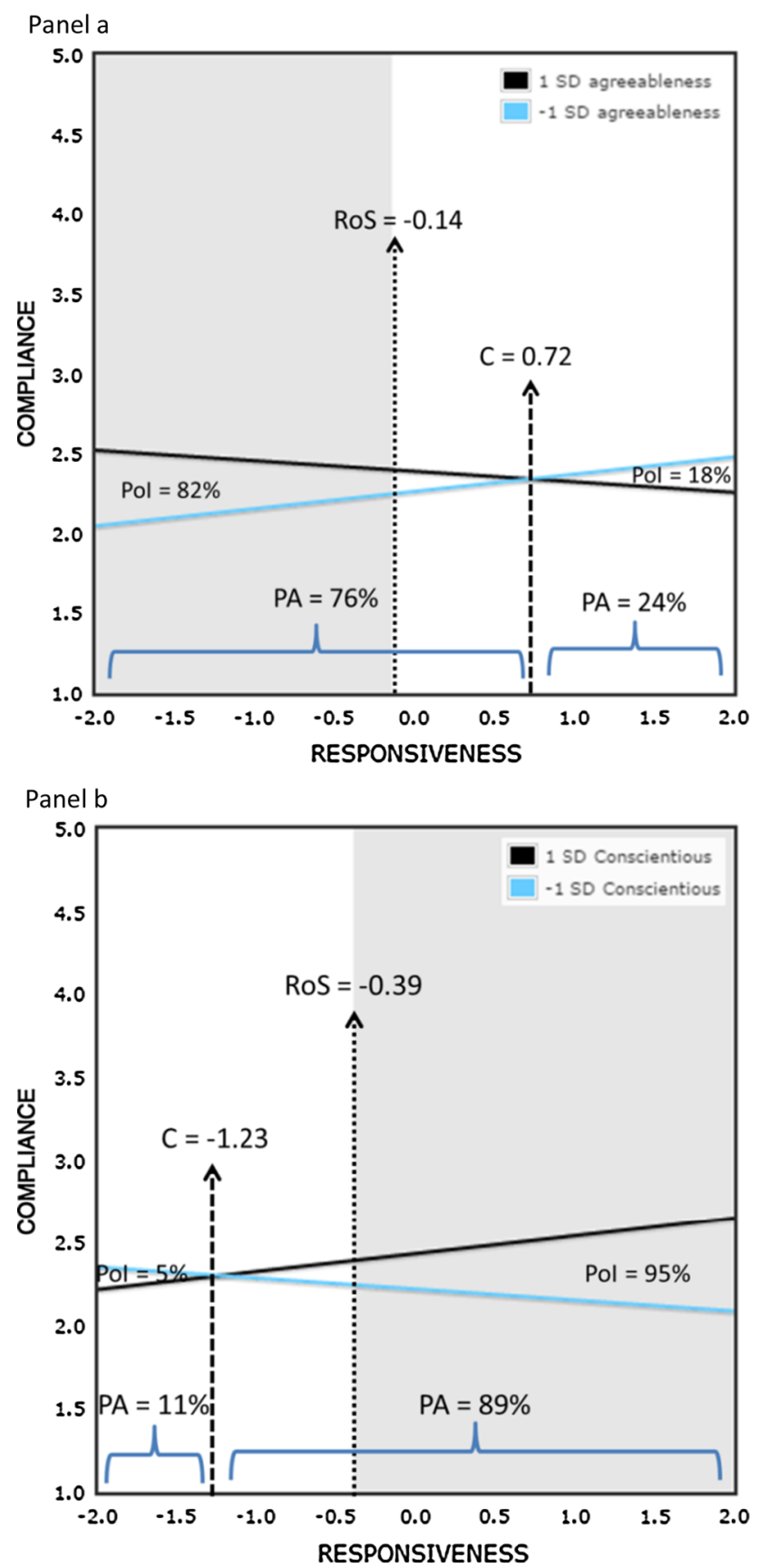

Fig. 3 Simple slopes of responsiveness predicting compliance at varying levels of agreeableness (panel a), and conscientiousness (panel b). High levels are $1 S D$ above the mean; low levels are $1 S D$ below the mean. The grey areas represent the regions of significance (RoS). The dotted lines represent the endpoints of the RoS on the $\mathrm{X}$-axis. The dashed line indicates the cross-over point $(\mathrm{C})$ of the regression lines on the $\mathrm{X}$-axis. The proportion of Interest (PoI) is the triangular area formed by the regression lines and this is the proportion of the interaction represented on the left versus right side of C. The proportion of Affected (PA) is calculated on the sample frequency of responsiveness and shows the proportion of reported levels of responsiveness higher than $\mathrm{C}$

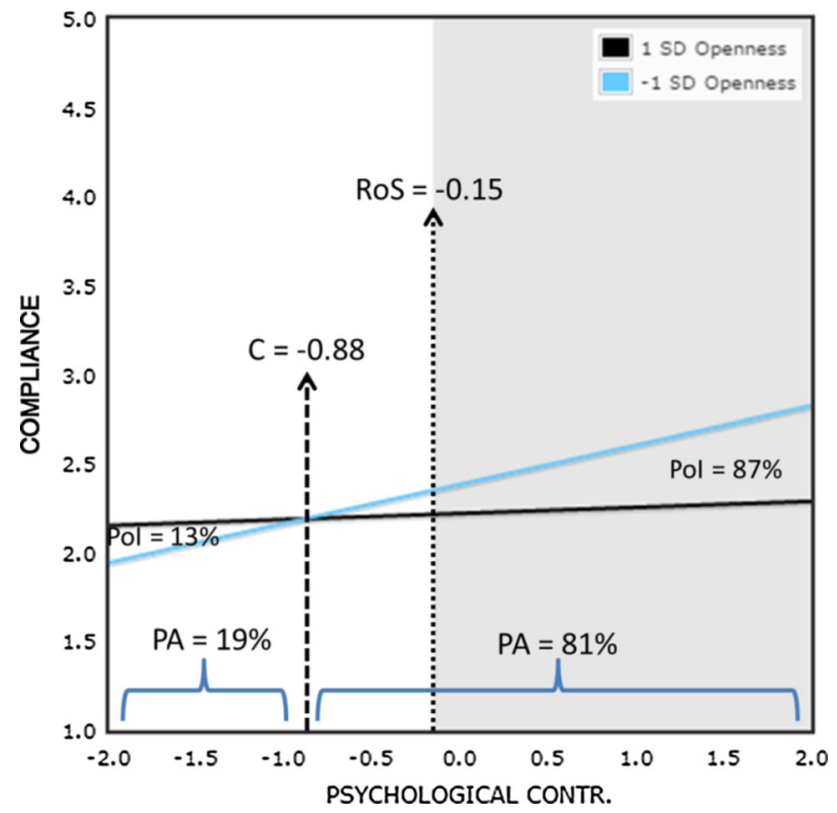

Fig. 4 Simple slopes of psychological control predicting compliance at varying levels of openness. High levels are $1 S D$ above the mean; low levels are $1 S D$ below the mean. The grey area represents the region of significance (RoS). The dotted line respresents the endpoint of the RoS on the X-axis. The dashed line indicates the cross-over point $(\mathrm{C})$ of the regression lines on the $\mathrm{X}$-axis. The proportion of Interest $(\mathrm{PoI})$ is the triangular area formed by the regression lines and this is the proportion of the interaction represented on the left versus right side of $\mathrm{C}$. The proportion of Affected (PA) is calculated on the sample frequency of responsiveness and shows the proportion of reported levels of responsiveness higher than $\mathrm{C}$

conflict resolution behaviors. Additionally, the meaningful interactions between parenting and personality in the prediction of conflict resolution indicate that some adolescents are more sensitive to particular parenting practices than others when it comes to resolving conflicts with mothers.

We found that adolescents who were raised in a warmer, more responsive climate used more positive problem solving and less withdrawal when having conflicts with their mothers. These findings were replicated across both informants. In previous studies, family support was also associated with relatedness and negotiation during conflicts (Allen et al. 2003; Rubenstein and Feldman 1993). Apparently, adolescents raised in a responsive climate try to resolve conflicts constructively. This is consistent with the view that warm parenting fosters an open climate for adolescents to disclose personal issues (Soenens et al. 2006). In contrast, we found psychologically controlling parenting to relate to more destructive resolution behaviors, such as conflict engagement, withdrawal, and compliance. Previous cross-sectional studies (Sturge-Apple et al. 2003; Yau and Smetana 1996) also showed that psychological 
control was associated with a more conflictuous climate. Hence, psychological control can evoke active as well as more passive conflict styles, with both being rather maladaptive in nature. Some adolescents who are raised in a manipulative and intrusive way react more passively to conflicts by avoiding them or merely giving into their parent (Assor et al. 2004). Other adolescents might feel more frustrated or angry by such manipulative parenting behaviors, resulting in more active reactions during conflicts, such as fighting and yelling.

It should be noted that the majority of findings with psychological control were replicated in the within-informant analyses of Study 1 and between Study 1 and Study 2 . However, these findings were not replicated in the acrossinformant analyses of Study 1, suggesting they could be partially attributed to shared method variance. The associations between responsiveness and problem solving and withdrawal did replicate in across-informant analyses. An alternative explanation for the lack of replication for the findings of psychological control as opposed to responsiveness in the across-informant analyses might be due to the visibility of both parenting dimensions and social desirability effects. Some adolescents might be less aware of their mother's use of psychological control as compared to their mother's use of supportive behaviors, and mothers might be more reluctant to report openly about manipulative parenting tactics than about supportive parenting behaviors. As a further illustration, the correlation between mother- and adolescent-reported psychological control was indeed lower than the correlation between mother- and adolescent-reported responsiveness ( $r=.34$, and .48 , respectively).

With regard to adolescent personality, some findings were in line with our expectations, whereas others were not. As expected, extraversion was associated with higher levels of problem solving and conflict engagement (i.e., active resolution styles), and lower levels of withdrawal and compliance (i.e., passive resolution styles) (Park and Antonioni 2007). Extraversion is indeed associated with elevated energy levels, positive emotions, and assertiveness, which could explain why extraverted adolescents have a tendency towards positive problem solving (Watson and Clark 1997). However, because extraversion is also related to impulsivity (Caspi et al. 2005), conflicts can evoke impulsive reactions resulting in higher conflict engagement. Extraverted individuals' assertive and actionoriented nature makes them less inclined to adopt more passive or withdrawal-oriented conflict strategies. As expected, more agreeable adolescents used more positive problem solving and less conflict engagement. This finding was in line with previous studies, indicating that agreeable people use constructive resolution styles to maintain their relationship with significant others (Jensen-Campbell and Graziano 2001; Jensen Campbell et al. 2003).
We expected conscientiousness to be associated with more positive problem solving, but instead we found a positive link with compliance. Conscientious people have been found to score high on self-regulation, which enables them to suppress aggressive impulses during conflicts (Jensen-Campbell and Malcolm 2007). Also, conscientious people are known to value integrity (Murphy and Lee 1994). Hence, in some cases, complying with parents might be the best strategy to adopt for conscientious individuals because this can prevent possible escalation of the conflict. Finally, openness predicted more conflict engagement in the regression analyses. A possible explanation might be that open adolescents might react more aggressively during a conflict when they perceive their mothers' interference as illegitimate and invasive of their privacy. This hypothesis is inspired by Smetana's domain theory (2006), stating that adolescents and parents differ in their perceptions of who has authority over certain issues. Several studies have demonstrated that parents and adolescents differ in their opinion about what belongs to the adolescent's personal domain, leading to conflicts (Yau and Smetana 1996). In addition, Luyckx et al. (2006) have demonstrated that open adolescents engage more in individuation and identity exploration. When adolescents perceive that their mothers restrict their personal exploration process, such a perception might explain why these adolescents adopt a self-focused conflict style such as conflict engagement. Future studies should examine how the conflict topic or domain and adolescents' perceptions of authority impact their conflict behaviors.

When comparing the associations of parenting and personality with adolescents' conflict resolution styles, parenting was the strongest predictor for all styles except for compliance. This suggests that conflict styles might be mainly shaped by parenting behaviors. In addition, it is noteworthy that the control variables explained a substantial proportion of the variance in the conflict resolution styles, mainly due to the inclusion of conflict frequency. Despite the strong association between the amount of weekly conflicts and conflict styles, both parenting and personality predicted adolescent conflict resolution styles directly and independently, underscoring the necessity to take both sets of variables into account.

Several associations between parenting and conflict resolution styles were moderated by adolescents' personality traits. More specifically, the main effects of responsiveness on problem solving, withdrawal, and compliance, and the main effect of psychological control on compliance were moderated by adolescents' personality. Hence, these main effects of parenting on conflict resolution have to be qualified based on adolescents' personality scores. However, no moderation occurred for the main effects of psychological control on conflict engagement and withdrawal, 
suggesting that psychologically controlling parenting is associated with more destructive resolution styles irrespective of adolescents' personality profile.

It should be noted that nine out of 40 tested interaction effects were significant $(23 \%)$ and, therefore, we should also regard the moderating role of personality as relatively modest. The pattern of findings indicates that some adolescents are more (or less) susceptible for the effects of parenting depending on their personality. This corresponds with the developmental contextual model (Lerner et al. 2012), which states that adolescents' behaviors result from the interaction of environmental and dispositional factors.

A particular strength of this study involved the formal testing of the nature of the interaction effects in terms of diathesis stress, vantage sensitivity, or differential susceptibility. The majority of the significant interactions supported the diathesis-stress perspective, meaning that the cooccurrence of adverse personality traits and parenting environments negatively impact on their conflict styles. For example, the link between responsive parenting and positive problem solving was moderated by extraversion. Introverted adolescents displayed lower levels of positive problem solving in a low-responsive climate as opposed to extraverted people, indicating that introverted adolescents seemed to suffer the most from a non-responsive climate with respect to their conflict resolution. Hence, extraversion may serve as a protective factor against a parenting climate which is characterized by low levels of warmth and support. The highly assertive nature of extraverted adolescents might make them less vulnerable for such adverse parental influences. Further, the association between responsiveness and compliance was moderated by agreeableness and emotional stability. In a low responsive climate, more friendly and less emotionally stable adolescents displayed more compliance during conflicts than their less friendly and more emotionally stable peers. Additionally, agreeableness, extraversion, and openness were found to moderate the link between psychological control and compliance. In contexts with high psychological control, introverted, friendly, and less open adolescents showed the highest levels of compliance. Especially for shy, less open, and agreeable adolescents, experiencing intrusive and controlling parenting makes them more inclined to give into their parents. The negative impact of this intrusive parenting style is reinforced by these adolescents' closed nature and lack of assertiveness, in that they do not feel able to defend their own opinion when experiencing a conflict. Furthermore, their motives to engage in this conflict style are probably induced by fear and low self-esteem. This explanation might especially hold for less open and more introverted adolescents and not so much for more agreeable adolescents. For the latter individuals, the explanation might be situated in their high concerns for maintaining a positive relationship (Graziano et al. 1996). This corresponds with a recent finding by Mabbe et al. (2015) that adolescents high on agreeableness do not act rebellious in response to a psychologically controlling home environment. Our finding extends this by stating that although being psychologically controlled by their mothers, these adolescents might do everything to keep the peace when experiencing conflicts.

Two interaction effects supported the vantage-sensitivity hypothesis. The negative association between responsiveness and withdrawal was moderated by agreeableness. Agreeable adolescents being raised in a warm, responsive climate reported lower levels of withdrawal than their less agreeable peers. These findings suggested that friendly adolescents benefit from being raised in a climate matching their personality. This in line with the findings of Meunier et al. (2011), demonstrating that highly agreeable children exhibited lower levels of externalizing behaviors in a supportive family climate. This pattern of findings can be situated in the goodness-of-fit model (Thomas and Chess 1977???), which states that a perceived match between people's goals and values and their environment is related to adaptive functioning. The vantage-sensitivity hypothesis was also confirmed for the interaction between responsiveness and conscientiousness in the prediction of compliance. Less conscientious adolescents seem to engage less in compliance than their more conscientious peers when raised in a rather warm family climate. A warm family environment might encourage less conscientious adolescents to speak freely during conflicts and obedience might be less important. In addition, less conscientious adolescents are less able to control their impulses during conflicts (Jensen-Campbell and Malcolm 2007), and noncompliance might be more accepted in a warm family climate.

Finally, the interaction between responsiveness and openness in the prediction of compliance was in favor of the differential-susceptibility perspective. In a highly responsive climate, less open adolescents benefit more from warm parenting in terms of reduced use of withdrawal, maybe because a responsive parenting climate (as opposed to a non-responsive climate) encourages less open adolescents to be less avoidant when faced with conflicts. A non-responsive climate, on the other hand, seems to reinforce their closed nature, resulting in avoidant behaviors during conflicts. For open adolescents, responsive parenting does not seem to impact on their use of withdrawal. It is also remarkable that most of the interaction effects were found in the prediction of compliance and withdrawal, suggesting that these more passive resolution styles are strongly dependent on the person-context interaction. 


\section{Limitations and Suggestions for Future Research}

Some study limitations need to be mentioned. First, the samples consisted primarily of Caucasian Dutch-speaking high school students. Therefore, we cannot state with certainty that our findings can be generalized to families from different ethnic backgrounds. Second, data were crosssectional, which prevents us from drawing conclusions about the direction of effects. In all regression analyses, parenting dimensions and personality traits were modeled as predictors of conflict resolution behaviors. This approach was adopted, in part, because previous studies have demonstrated that parenting influences adolescents' interpersonal functioning (Steinberg 2001). However, longitudinal studies have also provided evidence for childdriven effects, meaning that adolescents' behaviors impact on parenting behaviors (Steeger and Gondoli 2013). Negative conflict behaviors might indeed instigate some mothers who feel distressed and lack adequate emotion regulation capacities (Gondoli and Silverberg 1997) to adopt psychologically controlling techniques in order to regulate their adolescents. Inversely, adequate conflict resolution may strengthen parent-adolescent relationships and, hence, have an impact on the quality of parenting. In sum, parenting dimensions and conflict resolution styles most likely influence one another in a reciprocal fashion which might also be the case for personality traits and conflict resolution styles. Hence, more longitudinal research studying the dynamics between these constructs is needed.

Third, mainly adolescent self-report measures were used, which makes our data more sensitive to response biases and problems related to shared-method variance. However, our findings concerning parenting and conflict resolution were replicated across two informants (i.e., adolescents and mothers) and two samples, which strengthens the validity of our results. Still, observations or diary methods could shed a more realistic picture about what is going on during conflict interactions. Relatedly, future studies should examine other variables that are important in the associations between parenting, personality, and conflict resolution. Emotions may be particularly relevant to investigate in this context. Parent-adolescent conflicts can evoke a wide range of emotions (Jones 2001), which can motivate people to engage in certain resolution styles.

Future studies should also examine whether similar processes occur in the father-adolescent relationship. Relatedly, given the salience of peer relationship during adolescence, future research should investigate which aspects of close peer-relationships are related to conflict resolution styles with friends. In addition, it remains a challenge to discover the true impact of the conflict style compliance. It can be an adaptive way of dealing with conflicts when there is a high concern for the relationship (present in highly agreeable and conscientious adolescents). On the other hand, compliance can be rather maladaptive for adolescents' development because this style can be indicative of a maladaptive family climate with little room for the adolescent's opinion. Future studies should unravel the motives behind the use of this conflict style.

To conclude, the present study contributed to our knowledge base on determinants of adolescents' conflict resolution behaviors in the parent-adolescent context. First, we demonstrated that positive parenting was associated with more constructive resolution styles. Psychologically controlling parenting was related to more destructive resolution behaviors. Second, in addition to the parenting context, adolescents' personality was also significantly predicted their resolution styles. Third, practitioners working with disrupted families should bear in mind that not all adolescents respond equally to similar family climates. Especially adolescents with a more introverted personality profile (in terms of low scores on extraversion and openness) are more vulnerable to the effect of intrusive and non-responsive parenting, meaning that they will more likely adopt destructive conflict resolution styles. The use of these destructive styles will probably further deteriorate the parent-adolescent relationship which may result in a vicious cycle with detrimental long-term consequences for adolescents and their parents. Therefore, it is essential to assess parenting behaviors as well as adolescents' personality traits, and how they interact, in order to effectively treat families.

\section{References}

Achenbach, T. M. (1991). Manual for the youth self-report and 1991 profile. Burlington, VT: University of Vermont, Department of Psychiatry.

Adams, R. E., \& Laursen, B. (2001). The organization and dynamics of adolescent conflict with parents and friends. Journal of Marriage and Family, 63, 97-110.

Adams, R. E., \& Laursen, B. (2007). The correlates of conflict: Disagreement is not necessarily detrimental. Journal of Family Psychology, 21, 445-458.

Ahadi, S., \& Rothbart, M. K. (1994). Temperament, development, and the Big Five. In C. F. Halverson, D. Kohnstamm, \& R. Martin (Eds.), Development of the structure of temperament and personality from infancy to adulthood (pp. 189-208). Hillsdale, NJ: Erlbaum.

Allen, J. P., Hauser, S. T., O'Connor, T. G., Bell, K. L., \& Eickholt, C. (1996). The connection of observed hostile family conflict to adolescents' developing autonomy and relatedness with parents. Development and Psychopathology, 8, 425-442.

Allen, J. P., McElhaney, K. B., Land, D. J., Kuperminc, G. P., Moore, C. W., O'Beirne-Kelly, H., \& Kilmer, S. L. (2003). A secure base in adolescence: Markers of attachment security in the mother-adolescent relationship. Child Development, 74, 292-307. 
Antonioni, D. (1998). Relationship between the big five personality factors and conflict management styles. International Journal of Conflict Management, 9, 336-355.

Assor, A., Roth, G., \& Deci, E. L. (2004). The emotional costs of parents' conditional regard: A Self-Determination Theory analysis. Journal of Personality, 72, 47-88.

Barber, B. K. (1996). Parental psychological control: Revisiting a neglected construct. Child Development, 67, 3296-3319.

Barber, B. K. (2002). Intrusive parenting: How psychological control affects children and adolescents. Washington, DC: American Psychological Association

Belsky, J. (2005). Differential susceptibility to rearing influences: An evolutionary hypothesis and some evidence. In B. Ellis \& D. Bjorklund (Eds.), Origins of the social mind: Evolutionary psychology and child development (pp. 139-163). New York: Guilford.

Branje, S. J. T., Van Doorn, M., Van der Valk, I., \& Meeus, W. (2009). Parent-adolescent conflicts, conflict resolution types, and adolescent adjustment. Journal of Applied Developmental Psychology, 30, 195-204.

Capaldi, D. M., Forgatch, M. S., \& Crosby, L. (1994). Affective expression in family problem solving discussions with adolescent boys. Journal of Adolescent Research, 9, 28-49.

Caspi, A., Roberts, B. W., \& Shiner, R. (2005). Personality development. Annual Review of Psychology, 56, 453-484.

Cohen, J., Cohen, P., West, S. G., \& Aiken, L. S. (2003). Applied multiple regression/correlation analysis for the behavioral sciences (3rd ed.). Mahwah, NJ: Erlbaum.

Collins, W. A., \& Laursen, B. (2004). Changing relationships, changing youth: Interpersonal contexts of adolescent development. Journal of Early Adolescence, 24, 55-62.

Connor-Smith, J. K., \& Flachsbart, C. (2007). Relations between personality and coping: A meta-analysis. Journal of Personality and Social Psychology, 93, 1080-1107.

De Haan, A. D., Prinzie, P., \& Deković, M. (2010). How and why children change in aggression and delinquency from childhood to adolescence: Moderation of overreactive parenting by child personality. Journal of Child Psychology and Psychiatry, 51, 725-733.

Duriez, B., Soenens, B., \& Vansteenkiste, M. (2007). In search of the antecedents of adolescent authoritarianism: The relative contribution of parental goal promotion and parenting style dimensions. European Journal of Personality, 21, 507-527.

Eisenberg, N., Hofer, C., Spinrad, T. L., Gershoff, E. T., Valiente, C., Losoya, S., et al. (2008). Understanding mother-adolescent conflict discussions: Concurrent and across-time prediction from youths' dispositions and parenting. Monographs of the Society for Research in Child Development, 73(2), 1-180.

Fraley, R. C. (2012). Probing interactions in differential susceptibility research. University of Illinois. Retrieved from http://www. yourpersonality.net/interaction/ros3.pl

Goldberg, L. R. (1992). The development of markers for the big-five factor structure. Psychological Assessment, 4, 26-42.

Gondoli, D. M., \& Silverberg, S. B. (1997). Maternal emotional distress and diminished responsiveness: The mediating role of parenting efficacy and parental perspective taking. Developmental Psychology, 33, 861-868.

Graziano, W. G., Jensen-Campbell, L. A., \& Hair, E. C. (1996). Perceiving interpersonal conflict and reacting to it: The case of agreeableness. Journal of Personality and Social Psychology, $70,820-835$.

Havighurst, S. S., Kehoe, C. E., \& Harley, A. E. (2015). Tuning into teens: Improving parental responses to anger and reducing youth externalizing behavior problems. Journal of Adolescence, 42, $148-158$

Jaccard, J., \& Turrisi, R. (2003). Interaction effects in multiple regression ( 2 nd ed.). Thousand Oaks, CA: Sage.
Jaffee, W. B., \& D’Zurilla, T. J. (2003). Adolescent problem solving, parent problem solving, and externalizing behavior in adolescents. Behavior Therapy, 34, 295-311.

Janssens, A., Goossens, L., Van Den Noortgate, W., Colpin, H., Verschueren, K., \& Van Leeuwen, K. (2014). Parents' and adolescents' perspectives on parenting: Evaluating conceptual structure, measurement invariance, and criterion validity. Assessment, 22, 473-489.

Jensen Campbell, L., Gleason, K., Adams, R., \& Malcolm, K. (2003). Interpersonal conflict, agreeableness, and personality development. Journal of Personality, 71, 1059-1085.

Jensen-Campbell, L. A., \& Graziano, W. G. (2001). Agreeableness as a moderator of interpersonal conflict. Journal of Personality, 69, 323-362.

Jensen-Campbell, L. A., Knack, J. M., Waldrip, A. M., \& Campbell, S. D. (2007). Do Big Five personality traits associated with selfcontrol influence the regulation of anger and aggression? Journal of Research in Personality, 41, 403-424.

Jensen-Campbell, L. A., \& Malcolm, K. T. (2007). The importance of conscientiousness in adolescent interpersonal relationships. Personality and Social Psychology Bulletin, 33, 368-383.

Jones, T. S. (2001). Emotional communication in conflict. In F. Eadie \& P. E. Nelson (Eds.), The language of conflict resolution (pp. 81-104). Thousand Oaks, CA: Sage.

Kiff, C. J., Lengua, L. J., \& Zalewski, M. (2011). Nature and nurturing: Parenting in the context of child temperament. Clinical Child and Family Psychology Review, 14, 251-301.

Kurdek, L. A. (1994). Conflict-resolution styles in gay, lesbian, heterosexual nonparent, and heterosexual parent couples. Journal of Marriage and the Family, 56, 705-722.

Laible, D. J., \& Carlo, G. (2004). The differential relations of maternal and paternal support and control to adolescent social competence, self-worth, and sympathy. Journal of Adolescent Research, 19, 759-782.

Laursen, B. (1993). The perceived impact of conflict on adolescent relationships. Merrill-Palmer Quarterly, 39, 535-550.

Laursen, B., \& Collins, W. A. (1994). Interpersonal conflict during adolescence. Psychological Bulletin, 115, 197-209.

Laursen, B., Coy, K. C., \& Collins, W. A. (1998). Reconsidering changes in parent-child conflict across adolescence: A metaanalysis. Child Development, 69, 817-832.

Lengua, L. J. (2008). Anxiousness, frustration, and effortful control as moderators of the relation between parenting and adjustment in middle-childhood. Social Development, 17, 554-577.

Lerner, R. M., Rothbaum, F., Boulos, S., \& Castellino, D. R. (2012). Developmental systems perspective on parenting. In M. H. Bornstein (Ed.), Handbook of parenting: Vol. 2, Biology and ecology of parenting (2nd ed., pp. 315-344). Mahwah, NI: Lawrence Erlbaum Associates.

Luyckx, K., Soenens, B., \& Goossens, L. (2006). The personalityidentity interplay in emerging adult women: Convergent findings from complementary analyses. European Journal of Personality, $20,195-215$.

Mabbe, E., Soenens, B., Vansteenkiste, M., \& Van Leeuwen, K. (2015). Do personality traits moderate relations between psychologically controlling parenting and problem behavior in adolescents? Journal of Personality,. doi:10.1111/jopy.12166.

Manzeske, D. P., \& Stright, A. D. (2009). Parenting styles and emotion regulation: The role of behavioral and psychological control during young adulthood. Journal of Adult Development, $16,223-229$.

McCrae, R. R., \& Costa, P. T, Jr. (1987). Validation of the five-factor model of personality across instruments and observers. Journal of Personality and Social Psychology, 52, 81-90.

McCrae, R. R., \& Costa, P. T, Jr. (1997). Conceptions and correlates of openness to experience. In R. Hogan, J. A. Johnson, \& S. 
R. Briggs (Eds.), Handbook of personality psychology (pp. 825-847). San Diego, CA: Academic Press.

McCrae, R. R., \& John, O. P. (1992). An introduction to the five-factor model and its applications. Journal of Personality, 60, 175-215.

Meunier, J. C., Roskam, I., \& Browne, D. T. (2011). Relations between parenting and child's behavior: Exploring child's personality and parental self-efficacy as third variables. International Journal of Behavioral Development, 35, 246-259.

Monroe, S. M., \& Simons, A. D. (1991). Diathesis-stress theories in the context of life stress research: Implications for the depressive disorders. Psychological Bulletin, 110, 406-425.

Murphy, K. R., \& Lee, S. L. (1994). Personality variables related to integrity test scores: The role of conscientiousness. Journal of Business and Psychology, 8, 413-424.

Nakagawa, S. (2004). A farewell to Bonferroni: The problems of low statistical power and publication bias. Behavioral Ecology, 15, 1044-1045.

Park, H., \& Antonioni, D. (2007). Personality, reciprocity, and strength of conflict resolution strategy. Journal of Research in Personality, 41, 110-125.

Pluess, M., \& Belsky, J. (2013). Vantage sensitivity: Individual differences in response to positive experiences. Psychological Bulletin, 139, 901-916.

Prinzie, P., Onghena, P., Hellinckx, W., Grietens, H., Ghesquière, P., \& Colpin, H. (2003). The additive and interactive effects of parenting and children's personality on externalizing behavior. European Journal of Personality, 17, 95-117.

Roisman, G. I., Newman, D. A., Fraley, R. C., Haltigan, J. D., Groh, A. M., \& Haydon, K. C. (2012). Distinguishing differential susceptibility from diathesis-stress: Recommendations for evaluating interaction effects. Development and Psychopathology, 24, 389-409.

Rubenstein, J., \& Feldman, S. (1993). Conflict-resolution behavior in adolescent boys: Antecedents and adaptational correlates. Journal of Research on Adolescence, 3, 41-66.

Rueter, M. A., \& Conger, R. D. (1995). Interaction style, problemsolving behavior, and family problem solving effectiveness. Child Development, 66, 98-115.

Schaefer, E. S. (1965). Children's reports of parental behavior: An inventory. Child Development, 36, 413-424.

Schludermann, E. H., \& Schludermann, S. M. (1988). Children's Report on Parent Behavior (CRPBI-108, CRPBI-30) for older children and adolescents (Tech. Rep.). Winnipeg, MB, Canada: University of Manitoba, Department of Psychology.

Sillars, A., Canary, D. J., \& Tafoya, M. (2004). Communication, conflict, and the quality of family relationships. In A. L. Vangelisti (Ed.), Handbook of family communication (pp. 413-446). Mahwah, NI: Lawrence Erlbaum Associates.

Smetana, J. G. (2006). Social domain theory: Consistencies and variations in children's moral and social judgments. In M. Killen \& J. G. Smetana (Eds.), Handbook of moral Development (pp. 119-153). Mahwah, NJ: Erlbaum.

Soenens, B., Vansteenkiste, M., Luyckx, K., \& Goossens, L. (2006). Parenting and adolescent problem behavior: An integrated model with adolescent self-disclosure and perceived parental knowledge as intervening variables. Developmental Psychology, $42,305-318$.

Spilt, J. L., Van Lier, P. A. C., Branje, S. J. T., Meeus, W., \& Koot, H. M. (2015). Discrepancies in perceptions of close relationships of young adolescents: A risk for psychopathology? Journal of Youth and Adolescence, 44, 910-921.

Steeger, C. M., \& Gondoli, D. M. (2013). Mother-adolescent conflict as a mediator between adolescent problem behaviors and maternal psychological control. Developmental Psychology, 49, 804-814.

Steinberg, L. (2001). We know some things: Parent-adolescent relationships in retrospect and prospect. Journal of Research on Adolescence, 11, 1-19.

Sturge-Apple, M. L., Gondoli, D. M., Bonds, D. D., \& Salem, L. N. (2003). Mothers' responsive parenting practices and psychological experience of parenting as mediators of the relation between marital conflict and mother-preadolescent relational negativity. Parenting: Science and Practice, 3, 327-355.

Sullivan, K. T., Pasch, L. A., Johnson, M. D., \& Bradbury, T. N. (2010). Social support, problem solving, and the longitudinal course of newlywed marriage. Journal of Personality and Social Psychology, 98, 631-644.

Thomas, A., \& Chess, S. (1977). Temperament and development. New York: Brunner/Mazel.

Trifan, T. A., \& Stattin, H. (2015). Are adolescents' mutually hostile interactions at home reproduced in other everyday life contexts? Journal of Youth and Adolescence, 44, 598-615.

Tucker, C. J., McHale, S. M., \& Crouter, A. C. (2003). Conflict resolution: Links with adolescents' family relationships and individual well-being. Journal of Family Issues, 24, 715-736.

Van Doorn, M. D., Branje, S. J. T., \& Meeus, W. H. J. (2008). Conflict resolution in parent-adolescent relationships and adolescent delinquency. Journal of Early Adolescence, 28, 503-527.

Van Doorn, M. D., Branje, S. J., VanderValk, I. E., De Goede, I. H., \& Meeus, W. H. (2011). Longitudinal spillover effects of conflict resolution styles between adolescent-parent relationships and adolescent friendships. Journal of Family Psychology, 25, $157-161$.

Van Leeuwen, K. G., Mervielde, I., Braet, C., \& Bosmans, G. (2004). Child personality and parental behavior as moderators of problem behavior: Variables- and person-centered approaches. Developmental Psychology, 40, 1028-1046.

Vermulst, A. A., \& Gerris, J. R. M. (2005). QBF: Quick Big Five persoonlijkheidstest handleiding [Quick Big Five personality test manual]. Leeuwarden, The Netherlands: LDC Publications.

Watson, D., \& Clark, L. A. (1997). Extraversion and its positive emotional core. In R. Hogan, J. Johnson, \& S. Briggs (Eds.), Handbook of personality psychology (pp. 767-793). San Diego, CA: Academic Press.

Wood, V. F., \& Bell, P. A. (2008). Predicting interpersonal conflict resolution styles from personality characteristics. Personality and Individual Differences, 45, 126-131.

Yau, J., \& Smetana, J. G. (1996). Adolescent-parent conflict among Chinese adolescents in Hong Kong. Child Development, 67, $1262-1275$. 